\title{
Le collège Saint-Vincent des pères lazaristes de Damas : l'enseignement français en Syrie (1864-1967)
}

Résumé de la thèse de doctorat soutenue par Jérôme Bocquet, préparée sous la direction de M. le Professeur Daniel Rivet (université de Panthéon-Sorbonne Paris I) et présentée en décembre 2002.

Jérôme Bocquet

\section{OpenEdition}

\section{Journals}

Édition électronique

URL : https://journals.openedition.org/dhfles/1271

DOI : $10.4000 /$ dhfles. 1271

ISSN : 2221-4038

Éditeur

Société Internationale pour l'Histoire du Français Langue Étrangère ou Seconde

Édition imprimée

Date de publication : 1 juin 2004

ISSN : 0992-7654

Référence électronique

Jérôme Bocquet, « Le collège Saint-Vincent des pères lazaristes de Damas : l'enseignement français en Syrie (1864-1967) », Documents pour l'histoire du français langue étrangère ou seconde [En ligne], 32 I 2004, mis en ligne le 23 octobre 2011, consulté le 27 mai 2021. URL : http://journals.openedition.org/ dhfles/1271; DOI : https://doi.org/10.4000/dhfles.1271

Ce document a été généré automatiquement le 27 mai 2021

(C) SIHFLES 


\section{Le collège Saint-Vincent des pères lazaristes de Damas : l'enseignement français en Syrie (1864-1967)}

Résumé de la thèse de doctorat soutenue par Jérôme Bocquet, préparée sous la direction de M. le Professeur Daniel Rivet (université de Panthéon-Sorbonne Paris I) et présentée en décembre 2002.

\section{Jérôme Bocquet}

Situé dans le quartier chrétien de la vieille ville, le collège Saint-Vincent, tenu depuis 1787 par les pères de la Congrégation de la Mission, est depuis la fin du XIX siècle un des plus grands établissements scolaires de Damas. Acteur politique, religieux et culturel de ce que les publicistes au début du XXe siècle ont appelé la «France du Levant ", la mission des lazaristes se situe au croisement de la diplomatie française et de la politique orientale du Saint Siège, entre francophonie et latinisation. L'étude a pour but de faire revivre une époque disparue, celle des missionnaires partis outremer, celle d'une francophonie levantine emportée par la tourmente du nationalisme arabe. Dans le portrait du collège Saint-Vincent, d'un siècle à l'autre, il s'agit de retrouver l'histoire d'un lieu singulier, « au ras du sol» selon l'expression de Jacques Revel. Cette histoire originale, souvent différente de celle des autres établissements missionnaires latins en Orient, révèle les arcanes de la politique culturelle de la France au Levant et l'ambiguïté des liens entre la France et les sociétés missionnaires. Les lazaristes sont longtemps les seuls missionnaires français présents dans le Bilâd al-Shâm jusqu'au Mandat français dans les années 1930. L'établissement des pères lazaristes constitue donc un symbole de la présence française au Levant. La Congrégation de la Mission a été le fer de lance de la pénétration culturelle française dans les provinces syriennes de l'Empire ottoman. 


\section{Les avatars d'une mission française et catholique}

2 Celle-ci est installée depuis la fin du XVIII ${ }^{e}$ siècle en Syrie où elle a repris les missions abandonnées par les jésuites à la suppression de la Compagnie de Jésus en 1783. Depuis le $\mathrm{XIX}^{\mathrm{e}}$ siècle, l'expansion de la congrégation a continué en lien avec la colonisation. De nationalité française en majorité, les missionnaires sont envoyés de façon privilégiée dans l'Empire français. Au long du $\mathrm{XX}^{\mathrm{e}}$ siècle, la congrégation s'internationalise cependant. En 1947, est élu le premier supérieur général non français. Le transfert de la curie généralice en 1963 achève d'enlever à la congrégation son caractère français. Installé à Damas depuis 1864 à la suite de l'intervention française en Syrie après les massacres de juillet 1860, fermé en novembre 1914, le collège Saint-Vincent rouvre dans le sillage des armées arabes de Fayçal en octobre 1918. Mettant fin en juillet 1920 au rêve du royaume arabe, la bataille de Maysalûn permettra au collège lazariste de devenir "le collège français Saint-Vincent " protégé du haut-commissariat établi en Syrie depuis 1920. Durant ces années, il fait néanmoins face à la concurrence grandissante de nouveaux établissements d'enseignement plus modernes ou plus puissants, français ou syriens. Après l'indépendance du pays, l'établissement rouvre en octobre 1946 sous la tutelle du ministère syrien de l'Éducation nationale. L'arrivée du Baas semble porter un coup fatal à son enseignement. Les lazaristes impuissants assistent alors à l'enrégimentement de la société, au désastre de juin 1967, puis à la nationalisation des écoles privées en septembre 1967. C'est donc de leur couvent où ils se sont repliés après la fermeture de leur collège qu'ils assisteront en novembre $1970 \mathrm{au}$ coup d'État du général Asad et à son entreprise de "redressement » ouvrant la voie à la réouverture de leurs établissements à partir de 1974.

On nous propose une lecture à plusieurs échelles, passant de l'histoire d'un lieu à une histoire méditerranéenne. On observe alternativement l'intérieur d'une communauté latine, l'espace chrétien, de la rue «Azzarié » aux quartiers de Bâb Tûma et de Qassâ', l'environnement musulman, de la ville de Damas à la nation syrienne, enfin l'espacemonde, de l'empire colonial français au monde arabe. Le collège Saint-Vincent a constitué un des lieux de formation des élites de la nation syrienne. Après 1946, ne pouvant plus concourir au maintien de la domination coloniale, il a tenté de perpétuer une culture cosmopolite, française et latine avant d'être progressivement éliminé par le pouvoir nationaliste syrien baasiste. Antichambre de la position sociale, le collège Saint-Vincent a été tout à la fois le lieu de répétition de l'ancienne élite, culturelle, cosmopolite et francophile, et le creuset des nouvelles élites de la Syrie indépendante. L'échec de l'aventure de la Congrégation de la Mission à Damas marque la disparition de la figure du missionnaire occidental alors qu'à partir de 1945, l'arabisation de son enseignement puis l'étatisation de ses établissements remet en cause sa légitimité. La thèse s'incarne dans le temps long, sur plus d'un siècle, afin de mettre en évidence un modèle missionnaire à travers plusieurs générations de lazaristes et d'élèves. Celui-ci semble triompher dans les années 1920, mais n'assure pas sa pérennité face à la montée inéluctable d'un ordre national. Tout en se référant aux mythes de l'épopée missionnaire, comme les massacres des chrétiens de Syrie en 1860, nous pouvons dégager quelques dates charnières : 1914 marque la fin du système ottoman qui avait vu l'épanouissement des missions latines, 1925 voit simultanément le déclenchement de la « révolte druze » et l'arrivée du général Sarrail, l'homme du Cartel des gauches, comme haut-commissaire à Beyrouth, double symbole de la fin des rêves lazaristes d'un 
Levant chrétien, 1945 enfin signifie la fin de la présence française. Le « collège français Saint-Vincent » devient un collège étranger sous l'œil soupçonneux du pouvoir syrien. De la construction nationale de la Nahda à la radicalité du Baas, l'établissement missionnaire n'échappe pas à l'histoire nationale. L'aventure de la mission lazariste de Damas est celle d'un processus inéluctable d'ouverture et de dépossession du collège, celle de l'aggiornamento de l'Église latine, passant du temps de la mission triomphante à celui de l'Église de Vatican II.

\section{France coloniale et Église universelle}

4 Au nom d'un idéal civilisateur et émancipateur, la France était partie arracher les peuples à la barbarie. L'histoire des lazaristes en Syrie de 1860 à 1967, date de la nationalisation du collège, ressemble à celle de la vie et de la mort de l'impérialisme français au Levant. Jusqu'en 1945, le « collège français » garde des liens étroits avec la puissance française. La seconde moitié du XIX ${ }^{e}$ siècle n'est-elle pas le moment où les relations entre les congrégations missionnaires et la puissance européenne, devenue coloniale, se renforcent considérablement? Beaucoup plus que les jésuites, la Congrégation de la Mission apparait comme un des instruments de la politique impériale de la France. Comme les autres missionnaires dispersés dans l'Empire français avant la parution des grandes encycliques pontificales Maximum illud en 1919 et Rerum Ecclesiae en 1926, les lazaristes ne sont pas encore dans le temps des nationalismes et du droit des peuples à disposer d'eux-mêmes. C'est pourquoi il est idoine d'évoquer jusqu'aux années 1940 la « France coloniale » en Syrie et d'analyser la poursuite de la mission civilisatrice sous d'autres formes. Pour la diplomatie française, les lazaristes représentent un élément de la puissance française. Dans l'esprit du hautcommissariat, l'essor de l'instruction générale et la diffusion de la langue française contribuent à faire accepter la tutelle de la France d'une manière plus efficace que l'action politique.

5 Peut-on définir le modèle d'une école française en Orient? Les liens que tissent les lazaristes avec la métropole sont à la fois solides et ténus. Financé pour partie par le ministère des Affaires étrangères et des subsides publics et privés métropolitains, constamment soutenu par le personnel consulaire et diplomatique en poste à Damas, même aux pires heures des luttes contre les congrégations en métropole au début du $\mathrm{XX}^{\mathrm{e}}$ siècle, le collège sert aussi de source de financement pour les autres activités missionnaires à Damas. A la différence des pays arabes voisins, comme le Liban, qui vont faire l'expérience de la francophonie sans la France après l'indépendance, les écoles françaises en Syrie sont en revanche mal préparées au retrait de la France. Malgré un patriotisme affiché ostensiblement tout au long du siècle, les lazaristes dépendent enfin des autorités du Saint-Siège et entendent de plus en plus les discours pontificaux en faveur d'une intégration aux Églises locales. Bien avant Vatican II, les missionnaires envisagent à partir des années 1940 de nouer de nouvelles relations de collaboration et non plus de subordination avec les chrétiens orientaux, s'émancipant ainsi de la tutelle morale de la France. 


\section{Des archives missionnaires à l'histoire des sociétés}

6 Cela a également été une entreprise de sauvegarde d'une collection privée située au couvent lazariste à Bâb Tûma, un ensemble très riche mais en voie de destruction. Le travail s'appuie sur le dépouillement des archives rédigées par les missionnaires qui rendent une vision humaine de la présence culturelle française à Damas. On part donc du quotidien des lazaristes pour remonter jusqu'à l'élaboration à Paris ou à Rome d'une politique syrienne. Pour cela, l'auteur a donné la parole aux acteurs, à la parole officielle d'abord, celle du ministère des Affaires étrangères et de la Propaganda fide, mais surtout aux missionnaires, congréganistes et laïcs, de la France au Levant, aux lazaristes évidemment. On a voulu faire apparaître la réalité, presque intime, de la mission, recréer un terrain. D'un destin individuel, celui d'un collège français à Damas, surgissait aussi la vision d'une société chrétienne, sous protection à l'époque des accords de Mytilène ou sécularisés à l'ère du général Asad.

7 Le souvenir d'un âge d'or de la francophonie syrienne, qui aurait été celui d'une société orientale chrétienne "française " disparue, inscrit la thèse dans un débat historiographique auquel elle voudrait échapper: ni jugement nationaliste, ni célébration nostalgique néo-coloniale d'un temps disparu, d'une " passion française $~^{1}$, ni lecture pieuse d'une histoire congréganiste. Elle serait une histoire détachée à la fois des mythes nationaux, des poncifs sur les chrétiens d'Orient et sur l'action missionnaire, et enfin des préventions cléricales. L'ambition était d'écrire l'histoire, plus ou moins pathétique, de l'acculturation de la mission lazariste en Syrie. Beaucoup de travaux ont été publiés sur la présence culturelle européenne et sur le monde des missions dans la Méditerranée orientale, mais peu d'études avaient été réalisées sur des congrégations missionnaires en Syrie. L'étude s'inscrit globalement dans une historiographie plus générale. Depuis plusieurs années maintenant, les historiens ont pris conscience de l'importance des archives des congrégations religieuses, non seulement pour l'histoire interne de chacune d'elles, mais encore comme élément de l'histoire de la société. Dans l'esprit de la missiologie née au temps de la décolonisation en tentant de bannir les clichés historiographiques, la thèse aborde ainsi l'insertion des missionnaires dans la société locale au travers de la diffusion de dévotions et de pratiques, du contexte politique ou de la sociologie des élèves du collège.

Le collège Saint-Vincent est somme toute un lieu assez banal mais relève, selon le mot de Jacques Ricœur dans La mémoire, l'histoire, l'oubli, de «l'exceptionnel normal ». Derrière le destin ordinaire d'une institution missionnaire française au Proche-Orient, il faut lire celle d'un quartier, le quartier chrétien de Bâb Tûma au cœur de la vieille ville de Damas. C'est aussi l'histoire des relations franco-arabes en Syrie. Dans cette histoire, on voit les différents acteurs mettre en place leurs stratégies: la Congrégation de la Mission joue ainsi sur plusieurs échelles, avec ses pères résidant à Damas, la maison provinciale établie à Beyrouth, enfin la maison mère à Paris, avant que la Curie généralice ne soit symboliquement transférée à Rome après la fin de l'Empire français au milieu des années 1960. La réalité du pouvoir tient dans la capacité des lazaristes à exploiter la situation politique et sociale. Le collège Saint-Vincent représente en fin de compte un point minuscule de l'effervescence au Levant au $\mathrm{XX}^{\mathrm{e}}$ siècle, mais il a contribué aux grands phénomènes observés par les historiens en Syrie au cours du siècle dernier : impérialisme, latinisation et arabisation. 
9 L'auteur se propose donc d'écrire une histoire globale, politique, sociale, religieuse et culturelle sur près d'un siècle. La première partie de la thèse met en évidence des régularités dans le comportement des missionnaires. On a cherché à tracer le portrait même imparfait d'une jeunesse damascène. Alors que le rôle de la congrégation a été remis en cause par l'État, deux missions éducatives s'opposent : l'une est l'instrument de la formation d'un bon chrétien, l'autre est le lieu de propagande civique et de promotion sociale, c'est-à-dire une version laïque et nationale de la mission congréganiste. L'enseignement lazariste répond en effet à une demande plus vaste qu'à celle des seuls catholiques. Jusqu'en 1967, les missionnaires accueillent ainsi en nombre chrétiens orthodoxes, musulmans sunnites et minoritaires, druzes et alaouites, juifs et même protestants. La décision des chrétiens d'y inscrire leurs enfants correspond au choix de la réussite individuelle: l'espoir que l'instruction compense l'hypothétique promotion sociale de la communauté 2 . La deuxième partie de la thèse pose le problème de l'analyse du temps court avec un collège missionnaire confronté à la montée du nationalisme arabe. Tandis que la mission lazariste a fait le choix de la présence française sous le Mandat, l'État syrien tente d'éliminer l'emprise politique et culturelle de l'étranger. Par étapes successives, facilitées après l'indépendance, il prend le contrôle du collège lazariste par l'arabisation progressive des programmes et des structures d'enseignement, jusqu'à l'étatisation finale des écoles privées en 1967.

\section{NOTES}

1. R. Solé, L'Égypte, passion française, Paris, Seuil, 1997.

2. C. Mayeur-Jaouen, "Les chrétiens d'Orient au XIXe siècle ", in J.-M. Mayeur, dir., Histoire du christianisme, t. XIII, Paris, Desclée, 2000, p. 486. 